\title{
Dinâmicas Interacionais Textuais no Chat: análises gráficas com aporte da teoria da linguagem de Mikhail Bakhtin
}

\author{
Interactive dynamics in a chat: visual analysis from a \\ bakhtinian standpoint
}

\author{
Augusto Maurer \\ Universidade Federal do Rio Grande do Sul
}

Paloma Dias Silveira

Universidade Federal do Rio Grande do Sul

\author{
Tania Bischoff \\ Pontifícia Universidade Católica do Rio Grande do Sul
}

Resumo: O presente trabalho parte de um estudo das tecnologias para a educação, em que as interações textuais entre usuários, sendo estes alunos e professor, por meio da ferramenta chat, são o foco de análise. O chat viabiliza a interação síncrona e a distância entre usuários, e, geralmente, possui uma estrutura de programação que torna possível a participação de grandes grupos. Dessa forma, muitas instituições vêm utilizando-o como uma das ferramentas fundamentais para promover o ensino à distância. Propomos a análise do corpus de um chat resultante de uma aula síncrona e a distância, em que participou um grupo de estudantes de pós-graduação. Buscamos construir uma metodologia de análise de tal corpus, que nos possibilite visualizar dinâmicas das interações dialógicas entre os sujeitos. Para isso, nos valemos dos aportes da teoria da linguagem de Mikhail Bakhtin, que trata do conceito de dialogismo como princípio da produção de enunciados.

Palavras-chave: Educação a distância. Chat. Enunciado.

Abstract: This paper focuses on the development by its authors, elicited by an academic exercise consisting in the analysis of the cross-conversations/interactions which occurred during a pre-determined time span in a virtual learning environment emulating a classroom, of a generic visual approach to the representation of the discourse produced in this sort of environment, intended as an aid to render visible, in a topographical way, relevant and meaningful relations among variables and categories perceived by researchers in the typically fuzzy collections of textual data arisen from such contexts.

Keywords: Distance learning. Chat. Stated.

MAURER, Augusto: SILVEIRA, Paloma Dias; Bischoff, Tania. Dinâmicas Interacionais Textuais no Chat: análises gráficas com aporte da teoria da linguagem de Mikhail Bakhtin. Informática na Educação: teoria \& prática, Porto Alegre, v. 11, n. 2, p. 80-89, jul./dez. 2008.

\section{I ntrodução}

0 presente trabalho parte de um estudo das tecnologias para a educação, em que as interações textuais entre usuários, sendo estes alunos e professor, por meio da ferramenta chat, são o foco de análise. O chat, acoplado a um ambiente virtual de aprendizagem, viabiliza a interação síncrona e a distância entre usuários, e, geralmente, possui uma estrutura de programação que torna possível a participação de grandes grupos. Dessa forma, muitas instituições vêm utilizando o chat como uma das ferramentas fundamentais para promover 0 ensino a distância.

Neste âmbito, ao se realizarem aulas a distância, via chat, se produzem grandes corpora, registros resultantes das interações escritas entre alunos e professores. Tais corpora constituem importante e inovador material empírico para pesquisas que pretendem analisar interações em ambientes virtuais voltados para o ensino-aprendizagem, sob diferentes enfoques, seja sobre as relações professoraluno, metodologias, gêneros discursivos, en- 
tre outras. A partir daí introduz-se um campo fecundo para análise de textos produzidos em chat, resultantes de relações entre alunos e professores com o objetivo de construir conhecimentos, sendo tal o campo de inserção de nosso estudo.

Propomos a análise do corpus de um chat resultante de uma aula síncrona e a distância ${ }^{1}$, em que participou um grupo de estudantes de pós-graduação, nas áreas da educação e informática na educação. Pretendemos construir uma metodologia de análise de tal corpus, que nos possibilite visualizar dinâmicas das interações dialógicas entre os sujeitos. Para isso, nos valemos dos aportes da teoria da linguagem de Mikhail Bakhtin, que trata do conceito de dialogismo como princípio da produção de enunciados, que constituem elos na cadeia de comunicação verbal.

\section{Bakhtin, Filosofia da Linguagem e Tecnologias}

Mikhail Bakhtin, filósofo russo, posicionouse criticamente em relação aos formalistas russos $^{2}$, em meados dos anos de 1920, pelo modo como praticavam a lingüística e a poética. Criticava a concepção formalista de que a arte e a literatura teriam um fim em si mesmas, como se fossem objetos autônomos, sem relação com o mundo exterior, com outras obras, com os autores e os leitores.

Segundo Tzvetan Todorov (2003), Bakhtin criticava a focalização dos estudos nos processos, na composição, na coerência, ou seja, nos elementos internos da obra, sem levar em conta a sua inserção num contexto de produção. Entretanto, Bakhtin não se deteve na oposição aos formalistas russos. O tema que estava no centro de seu interesse, situado no campo da estética, referia-se à relação entre autores e seres criados, entre autor e herói, ainda, entre autor e personagem ou obra.

\footnotetext{
1 Tal chat provém da quarta aula de uma disciplina do curso de Pós-Graduação em Educação e, concomitantemente, do curso de Pós-Graduação em Informática na Educação (UFRGS), realizada no dia 03 de abril de 2008, no período das $14 \mathrm{~h} 15 \mathrm{~min}$ às $19 \mathrm{~h} 02 \mathrm{~min}$ horas, em que participaram 19 alunos e alunas e um professor. Cabe destacar que a temática de estudo da disciplina era a interação em ambientes telemáticos sob a perspectiva de filosofia da linguagem de Mikhail Bakhtin.

2 Tratava-se de um grupo de críticos, lingüistas e escritores russos, com talento e prestígio incontestáveis, que mantinham relações incertas com o marxismo e não dominavam as instituições (TODOROV, 2003).
}

Bakhtin considera que a unidade mínima da interação humana, oral ou escrita, é o enunciado, incluído na comunicação discursiva de dado campo (TODOROV, 2003, p. 309).

O enunciado é a unidade real da comunicação, distinguindo-se das unidades convencionais da língua, como as palavras e orações. Para Bakhtin, o que define o enunciado como unidade, compondo seus limites, é alternância de sujeitos do discurso, ou seja, a alternância dos falantes. Aí reside a diferença entre enunciado e oração: "Os limites da oração enquanto unidade da língua nunca são determinados pela alternância dos sujeitos do discurso." (TODOROV, 2003, p. 277)

Além disso, somente o sistema da língua é suscetível de repetição. Pois, “[...] a reprodução do texto pelo sujeito (a retomada dele, a repetição da leitura, uma nova execução, uma citação) é um acontecimento novo e singular na vida do texto, o novo elo na cadeia história da comunicação discursiva." (TODOROV, 2003, p. 311)

O texto, então, não é visto como um conjunto de orações compostas por palavras, mas como um enunciado singular.

O enunciado nunca é apenas um reflexo, uma expressão de algo já existente fora dele, dado e acabado. Ele sempre cria algo que não existia antes dele, absolutamente novo e singular, e que ainda por cima tem relação com o valor (com a verdade, com a vontade, com a beleza etc.). Contudo, alguma coisa criada é sempre criada a partir de algo dado (a linguagem, o fenômeno observado da realidade, um sentimento vivenciado, o próprio sujeito falante, o acabado em sua visão de mundo etc.). Todo o dado se transforma em criado (TODOROV, 2003, p. 326).

Todo enunciado ou texto possui um destinatário, do qual o autor espera uma compreensão de natureza responsiva ativa: “Toda a compreensão é prenhe de resposta, e nessa ou naquela forma a gera obrigatoriamente: o ouvinte se torna falante [...]" (BAKHTIN, 2003, p. 271).

Dois enunciados, ao entrarem em relação, um em resposta ao outro, estabelecem uma relação dialógica. Tais relações se dão entre textos e no interior de um texto (BAKHTIN, 2003, p. 309). É importante considerar que, segundo Bakhtin, os enunciados não se definem apenas pelo diálogo no seu sentido mais comum, ou seja, não se limitam às réplicas do 
diálogo real, cotidiano que se estabelece entre sujeitos. Pois,

[...] dois enunciados distantes um do outro, tanto no tempo quanto no espaço, que nada sabem um sobre o outro, no confronto dos sentidos revelam relações dialógicas se entre eles há ao menos alguma convergência de sentidos (ainda que seja uma identidade particular do tema, do ponto de vista etc.) (BAKHTIN, 2003, p. 331)

No entremeio dessas relações dialógicas entre enunciados instaura-se a produção de sentidos, à medida que os sentidos se estabelecem na resposta de um enunciado a outro.

Para Bakhtin, o sentido depende da relação entre sujeitos em um contexto, de forma que “[...] só se atualiza no contato com outro sentido, o sentido do outro [...] Por isso, não pode haver um sentido primeiro ou último, pois o sentido se situa sempre entre os sentidos, elo na cadeia do sentido que é a única suscetível, em seu todo, de ser uma realidade." (BAKHTIN, 2003, p. 386)

Atualmente, estudiosos de diversas áreas, como linguistas, psicólogos, informatas voltados ao desenvolvimento de ambientes virtuais, tem voltado seu interesse para a comunicação discursiva em ambientes telemáticos, com o objetivo de compreender as relações dialógicas estabelecidas a partir da interlocução virtual, em espaços como o chat, num tempo síncrono, e no fórum, no tempo assíncrono. Tais estudos vêem o ambiente virtual como espaço de produção de linguagem, e muitos se fundamentam nas contribuições da teoria enunciativa da linguagem de Bakhtin.

Nesse contexto, citamos os trabalhos de Axt et al. (2003, 2006) com foco na Autoria Coletiva, em que se analisa a produção textual coletiva, realizada por meio de diferentes ferramentas tecnológicas, como ambientes virtuais de aprendizagem e ferramentas voltadas especificamente à escrita colaborativa via web.

Bernardes e Vieira (2001), também com foco na produção da escrita na internet, analisam a especificidade da situação na qual os enunciados são produzidos, bem como os sentidos que emergem em processos de interlocução.

O leque de práticas comunicativas atravessadas por avanços na ciência da informação traz consigo novas formas de discurso e novas formas de escrita desafiando, constantemente, quando se pretende seu entendimento, aos diversos pressupostos teóricos calcados em estudos da linguagem.

Dentre as diversas concepções que historicamente buscaram lançar alguma luz sobre a comunicação humana, em sua modalidade verbal, entendemos que o dialogismo de Mikhail Bakhtin (2003), centrado na interdependência das posições enunciativas, é uma teoria que possibilita problematizar o fenômeno da interação humana e suas diversas produções de sentido, instauradas em ambientes de interação virtual.

Dentre as diversas modalidades de interação virtual atualmente disponíveis (chat, fórum, blog, teleconferência, entre outros), nos parece que o chat ou bate-papo:

- $\quad$ tanto por sua formatação pouco afeita aos regimes monológicos de sobrecodificação do si pelo outro (AXT, 2006);

- $\quad$ pela livre configuração do fluxo de posições enunciativas entre seus participantes; e,

- pela instantaneidade da instauração de posições responsivas, se configura como um dos meios mais caros às comunidades virtuais desterritorializadas em que, via brainswriting (tempestade de idéias escritas), levantam-se aspectos e nuances a afetar objetos de estudo, discussão ou observação em quaisquer campos de conhecimento ou esfera de comunicação.

\section{Corpus Chatiano em Análise}

Diante de um corpus que totaliza 23 páginas, composto por interações textuais escritas, numa situação de diálogo entre um grupo de estudantes de pós-graduação, primeiramente nos detivemos na codificação do texto, utilizando, para tanto, uma planilha Microsoft Excell.

Optamos por um fio condutor para sistematizarmos a leitura dos dados, calcados em princípios da análise de conteúdo, a qual conforme sustenta Moraes:

[...] constitui-se de um conjunto de técnicas e instrumentos empregados na fase de análise e interpretação de dados de uma pesquisa, aplicando-se, de modo especial, ao exame de documentos escritos, discursos, dados de comunicação e semelhantes, com a finalidade de uma leitura crítica e aprofundada, levando à descrição e interpretação destes materiais [...]. (MORAES, 2007, p. 104) 
A análise de conteúdo é um processo de categorização que consiste na decomposição de um texto nos seus diferentes elementos, classificando-os em categorias e subcategorias. Segundo afirma Bardin (1988, p. 105): “Fazer uma análise temática consiste em descobrir os núcleos de sentido que compõe a comunicação e cuja presença, ou freqüência de aparição, podem significar alguma coisa para o objetivo analítico escolhido."

Tal tipo de metodologia tem como propósito captar outros significados que, muitas vezes estão latentes no conteúdo das pesquisas, mas somente uma análise mais aprofundada é capaz de detectar, de apreender. É um procedimento metodológico que permite um detalhamento e análise minuciosa do conteúdo pesquisado e garante a cientificidade do processo e da apuração dos resultados.

A análise de conteúdo do material empírico foi estruturada conforme o que postula Bardin (1988) seguindo três etapas: Pré-análise; Exploração do material; Tratamento dos resultados obtidos e interpretação.

Num primeiro momento foi feita uma leitura flutuante do material, com o propósito de realizar um mapeamento dos focos temáticos de discussão ocorridas no Chat. E, a partir desta leitura, foram criadas unidades temáticas de registro.

Conforme destaca Bardin (1988, p. 104), unidade de registro "[...] é a unidade de significação a codificar e corresponde ao segmento de conteúdo a considerar como unidade de base, visando à categorização e a contagem frequencial."

Depois de realizado o trabalho de seleção das unidades de registro, procedeu-se ao processo de categorização, quando os temas, frases ou palavras de significados semelhantes foram reunidos em distintas categorias. Após uma leitura livre e flutuante do chat, ou seja, das 696 interações textuais entre os usuários, identificamos 9 categorias denominadas de acordo com os núcleos temáticos a que se referiram.

Diante das categorizações, consideramos que apoiarmo-nos somente na Análise do Conteúdo não atenderia à dinamicidade, pluralidade e complexidade do objeto em análise, pois estaríamos sustentados num quadro metodológico que não nos viabiliza instrumentos para compreender a interatividade enunciativa que define uma visão dialógica de comunicação.
Desta forma, buscamos em M. Bakhtin uma concepção da comunicação discursiva como rede dinâmica de conexões entre enunciados de autores diversos. Por isto, passamos a nos questionar sobre como avançar nesta metodologia, com o fim de construir uma metodologia que nos possibilite visualizar as dinâmicas das interações dialógicas entre os sujeitos, via chat, tendo em vista que: (i) a grande adequação do quadro teórico desenvolvido por Bakhtin para o exame de ambientes telemáticos, favoráveis à exponenciação da conectividade, tanto em amplitude (quantidade e aterritorialidade de interlocutores) como em freqüência enunciativa, tais como chats, fóruns, blogs e afins; e (ii) a concepção dialógica da comunicação discursiva formulada por Bakhtin de certo modo antecipa, na lingüística e nas ciências humanas, abordagens tais como quanta, grupos, grafos, fractais ou redes neurais, portanto, julgamos oportuno e instigante auscultar a rede de conexões instaurantes de sentido ocorrentes em um chat de apoio à aprendizagem com referenciais bakhtinianos, através de um estilo particular de análise, ao qual denominamos análise gráfica, concebido ao nos depararmos com as potencialidades e, ao mesmo tempo, as limitações da análise de conteúdo.

Ao idealizarmos um modo de visualizar graficamente a ocorrência de enunciações no Chat, ao longo de seu eixo temporal e discriminadas em faixas correspondentes a seus autores, vislumbramos a possibilidade de isolar em diagramas distintos as falas correspondentes às convergências temáticas recorrentes identificadas no corpus - tanto daquelas temáticas originalmente propostas na disciplina quanto daquelas emergentes da interatividade discursiva - que melhor permitissem a observação do desenvolvimento de sub-conversações sobre cada tema, bem como o maior ou menor grau de envolvimento da comunidade interativa em cada um deles.

Metodologicamente, o processo de representação gráfica das subconversações (categorias de análise) temáticas presentes no corpus obedeceu às seguintes etapas:

- Quantificação da extensão de cada fala - enunciado -, de aluno ou professor, em função do número de caracteres do respectivo texto.

- Identificação, mediante a leitura linear do corpus, de categorias de convergência 
temática.

- Qualificação de cada fala do corpus como pertencente a uma ou mais das categorias temáticas anteriormente identificadas.

- Agrupamento, em tabelas distintas, dos atributos (tempo e extensão) das falas relativas a cada área de convergência temática.

- Mapeamento de distribuição das extensões das falas de cada tabela temática em uma matriz bidimensional, tendo num eixo a duração temporal do chat e no outro a designação de cada participante, na qual uma extensão zero é atribuída, a cada intervalo temporal, a cada autor em silêncio naquele instante.

- Inversão das matrizes acima, substituindo-se linhas por colunas e vice-e-versa, a fim de adequá-las a uma forma popular e acessível de visualização gráfica (Microsoft Graphics, disponível no Excell e no Word) que represente as falas de cada autor com uma mesma cor.

- Plotagem das matrizes temáticas invertidas como colunas seqüenciais.

- Cada categoria representada no gráfico, em que os sujeitos são identificados por cores, demonstrando o quanto participou pela coluna colorida (quanto mais caracteres do enunciado, mais elevada a coluna), no tempo x que durou a sua verbalização. Quando não se manifesta é porque o aluno ou professor está em silêncio naquele assunto.

Optamos, também, por apresentar gráficos de sobreposição das categorias, a fim de visualizar, com o leitor, os movimentos que acontecem no Chat, para posterior análise do que identificamos neste momento.

Cabe destacar que especificamente duas categorias serão objeto de análise, visto que têm relação com o conteúdo da disciplina os Estudos em Bakhtin e a Relação Professor-Aluno. As demais são apresentadas para configurar os movimentos do Chat na linha do tempo.

As visualizações gráficas assim obtidas ensejaram ou contribuíram para constatações quanto aos seguintes aspectos:

- Ordem de relevância temática no chat.
- Distribuição (hegemônica ou ocasional, tanto ao longo do chat como quanto ao número de sujeitos envolvidos) de cada discussão temática.

- $\quad$ Atuação do professor/moderador.

\section{As Temáticas que Atravessaram as I nterações Entre os Sujeitos}

De um total de 696 interações,

- $\quad \mathbf{1 9 8}$, ou seja, $\mathbf{2 8 , 4 4 \%}$ ocorreram devido às Entradas e Saídas do Chat, o que é constante devido aos problemas de rede e conexões. Alguns participantes tendem a sair e retornar, no mesmo chat, após períodos de tempo. Este percentual interferiu no andamento do chat, pois aconteciam diversas interrupções, principalmente quando os alunos retornavam em situações que os temas de discussão já haviam avançado consideravelmente.

- As Combinações do Trabalho em Grupo a ser realizado ocorreram no início e no término do mesmo, com um total de 177 intervenções, totalizando 25,43\% .

- Em relação ao tema proposto do Chat, Estudos em Bakhtin, ocorreram 144 interações, o que representa $\mathbf{2 0 , 6 8 \%}$ das intervenções da totalidade do chat.

- A Relação Professor-Aluno é analisada no Chat com 82 intervenções, o que representa $\mathbf{1 1 , 7 8 \%}$ deste. Optamos por trabalhar especificamente com estas duas temáticas - Estudos em Bakhtin e Relação Professor-Aluno. As demais categorias serão referidas visando complementar às análises realizadas.

Das verbalizações restantes que atravessaram o chat:

- $\quad 4,59 \%$ (32) - designadas como Falas \& Ruídos - pertencem ao âmbito de uma conversação tipicamente oral, de ordem privada, interpessoal, social ou doméstica, tais como, por exemplo, profissão, família, entre outros.

- 4,07\% (28) referem-se ao Chat em si. Constam nesta categoria enunciações a respeito do uso do chat como ferramenta para a educação a distância, suas potencialidades e limitações;

- 2,29\% (16) são relativos a Proble- 
mas com o Computador, tais como velocidade de CPU ou dificuldade de conexão;

- $\mathbf{2 , 0 1 \% ~ ( 1 4 ) ~ c o n t e ́ m ~ i n t e r a c ̧ o ̃ e s ~ d e ~}$ alunos em Francês, sugerindo, uma tendência da criação de uma sub-comunidade de comunicação semi-privada.

- $\quad 0,71 \%(5)$ a respeito de conceitos do autor M. Foucault.

O seguinte gráfico, elaborado na fase inicial da pesquisa, em que se trabalhou com pressupostos da análise de conteúdo, mostra a relação quantitativa entre as freqüências enunciativas em cada categoria, através do número de enunciados proferidos durante o chat, em cada campo temático.
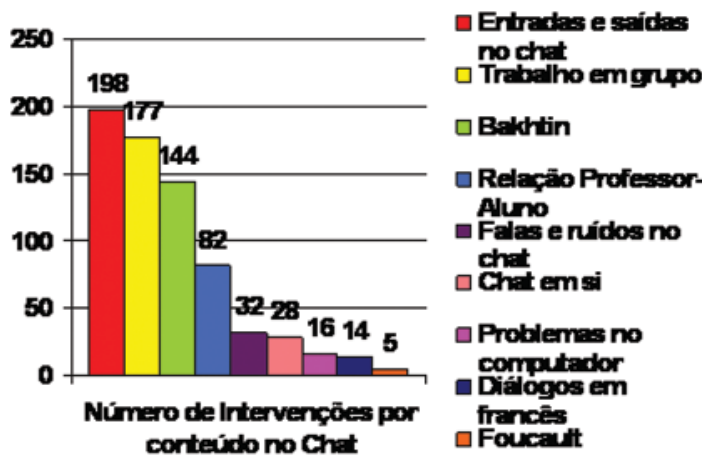

GRÁFICO 1 - Freqüência Enunciativa Temática no Chat

Após a tabulação e quantificação das falas segundo os eixos temáticos evidencia-se, como preocupação de primeira ordem dos participantes, a discussão diretamente relacionada ao objetivo da disciplina, de idéias concernentes ao pensamento lingüístico, crítico e filosófico de Mikhail Bakhtin. Também destacam-se as enunciações acerca de relações entre professor e aluno. Observa-se que o chat representado no corpus manteve um elevado grau de focalização em seu objetivo pedagógico, contribuindo para o debate em torno da validação do protocolo chat como recurso telemático de aprendizagem.

\section{O Chat Dinâmico}

Para obter visualizações espaciais tridimensionais da atividade dialógica virtual (de outra materialidade) que explicitassem a alocação dinâmica de interesses da comunidade em estudo e, ao mesmo tempo, de cada um de seus membros, por cada categoria temática identi- ficada, plotamos, nos próximos três gráficos, enunciações durante todo o chat, pertencentes às três áreas temáticas de diálogo mais intenso.

Em outras palavras, os próximos gráficos representam conversações em cada um dos principais eixos temáticos, isoladas de conversações simultâneas ou qualquer ruído. Neles, colunas verticais representam enunciados individuais. A altura de cada coluna é proporcional à extensão, em número de caracteres, do enunciado que representa.

As legendas abaixo dos gráficos representam os falantes, com diferentes cores.

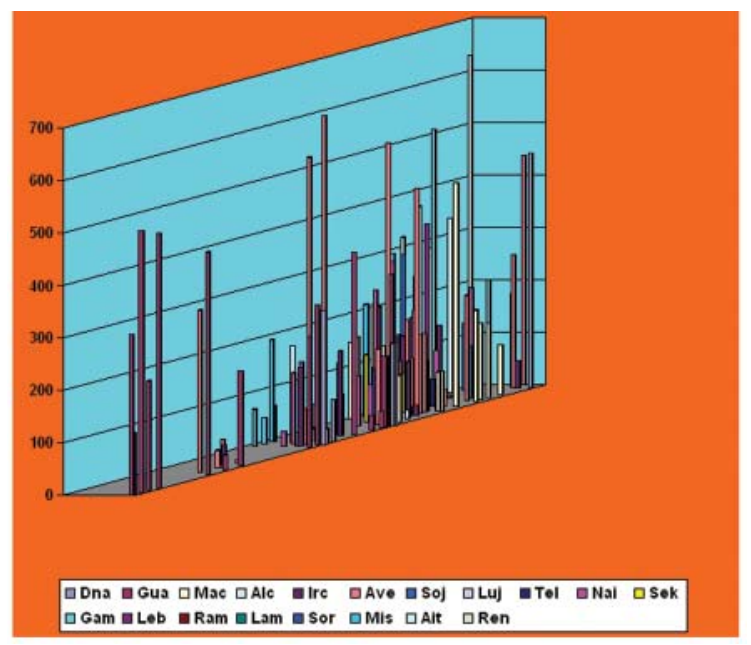

GRÁFICO 2 - Enunciados Acerca dos Estudos 1

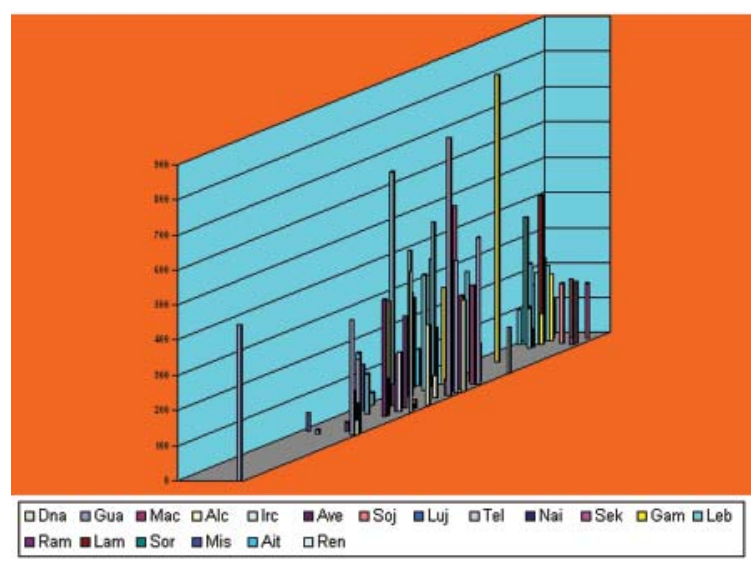

GRÁFICO 3 - Enunciados Acerca da Discussão Sobre Relacionamento Professor-Aluno 


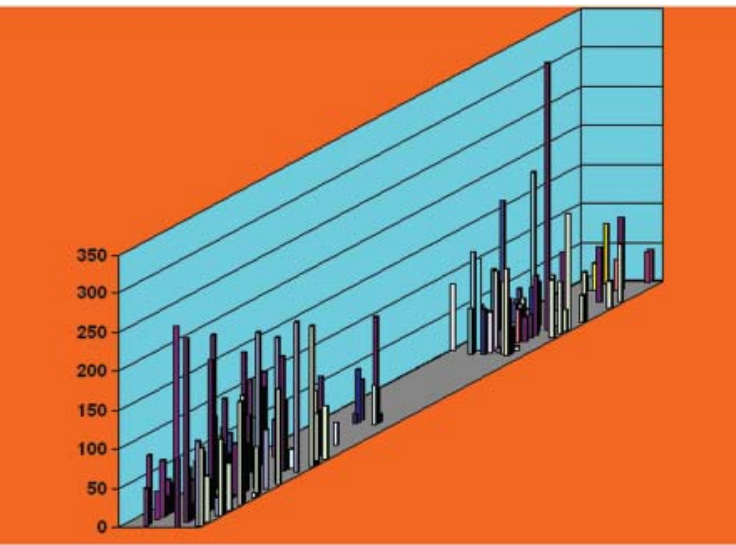

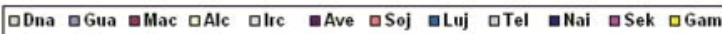
aLeb $₫$ Ram $\backsim$ Lam $₫$ Sor $\square$ Mis aAit aRen

GRÁFICO 4 - Enunciados Sobre Combinações 1

A distribuição de enunciados nos três gráficos anteriores, que evidenciam comportamento enunciativo coletivo e individual, indica:

- Que mais participantes do chat envolveram-se em discussões acerca do objeto principal da disciplina, a saber, a teoria da linguagem de Mikhail Bakhtin, do que nas outras duas áreas temáticas, a saber, os agenciamentos em torno de um trabalho de conclusão da disciplina (em grupos) e as relações entre professor-aluno. Tais evidências, i.e., a de que os alunos que freqüentaram o ambiente de aprendizagem na ocasião ativeram-se, além de ao objeto formal de estudo, predominantemente a questões inerentes à disciplina e à área temática à qual esta se insere, indicam a potencialidade do chat enquanto recurso de aprendizagem. Contribuem também, ao nosso ver, à intensa responsividade e liberdade enunciativa.

- A decisiva atuação do professor-moderador, como espinha dorsal a atravessar o chat, pautando, focalizando e esclarecendo as questões mais relevantes por onde flutuou o interesse dos participantes.

- A concentração de diálogos acerca de objetos de estudo centrais e secundários (Bakhtin e relação entre professor-aluno) mais próximo ao horário de pico interativo - a sugerir, por sua vez, pela enunciação mais freqüente quando da maior presença da classe no ambiente, uma vontade discursiva mais prenhe de responsividade no que tange ao debate sobre os mesmos.

- A concentração, por outro lado, de agenciamentos mais pontuais e/ou particulares acerca da agenda acadêmica em outros momentos, nem tão dedicados, como vimos, ao(s) objeto(s) de estudo da disciplina.

- $\quad$ O maior grau de elaboração lógica, típico da linguagem científica, de enunciados relativos aos objetos de estudo (quantificados por sua extensão em número de caracteres), se comparado ao de enunciações relativas à agenda acadêmica, mais próximos, estes, de falas da linguagem cotidiana.

Após representar as dinâmicas de sujeitos, sobretudo individualmente, em gráficos distintos para diferentes eixos temáticos presentes no chat, procedemos à plotagem simultânea, ao longo da duração do chat, dos diálogos relativos à cada núcleo temático, sem distinção de sujeito. Desta forma, podemos observar nos seguintes diagramas, nos quais desmembramos o chat em três segmentos temporais consecutivos (início, meio e final) no intuito de obtermos uma melhor resolução gráfica, a maior ou menor densidade de ocorrência, a cada instante do chat, de interação dialógica em cada área temática freqüentada por seus participantes, bem como relações de simultaneidade e alternância entre destes diálogos.

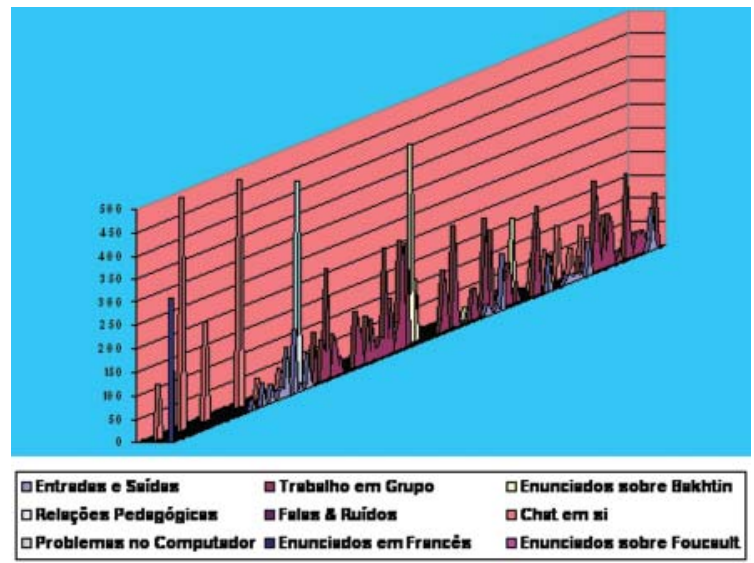

GRÁFICO 5 - Início do Chat 


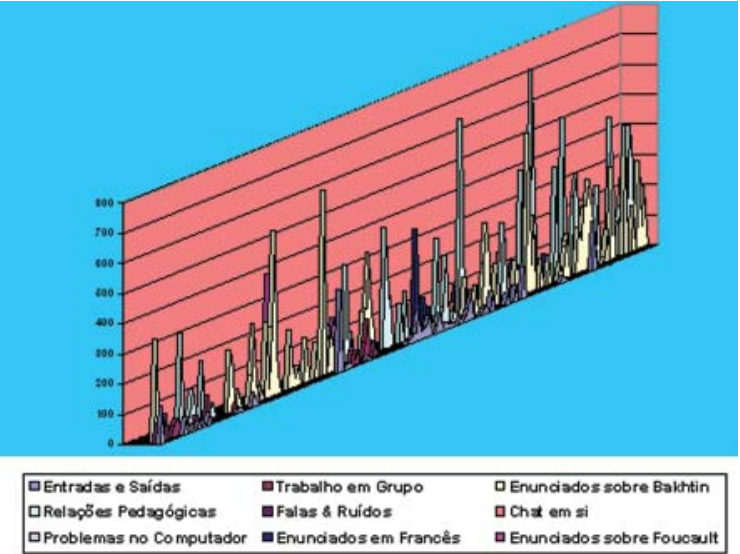

GRÁFICO 6 - Meio do Chat

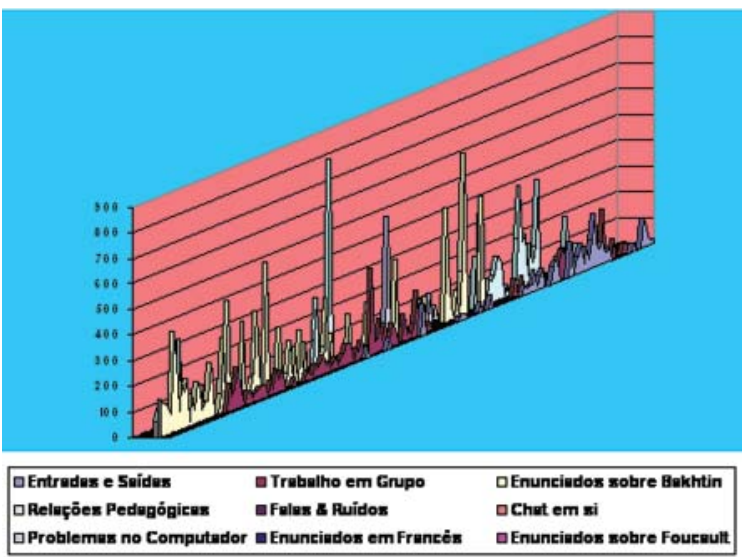

GRÁFICO 7 - Final do Chat

Os três gráficos acima evidenciam, principalmente a predominância de ocorrência de conversações sobre eixos temáticos majoritários em momentos específicos do chat, em oposição à dispersão relativamente mais homogênea ao longo do chat, daquelas conversações de menor freqüência enunciativa, geralmente mais pontuais ou de interesse mais particular.

Em outras palavras, verificamos que, enquanto os breves comentários sobre os conceitos de M. Foucault, equipamentos, o chat em si ou ainda em francês ocorrem aleatoriamente, sem obedecer a nenhuma lógica aparente em relação ao tempo de transcurso do chat, já enunciações acerca dos principais centros de interesse visitados durante o mesmo - também, significativamente, as mais numerosas - tenderam a ocorrer em momentos cronológicos bem mais delimitados.

\section{Considerações Finais}

A análise gráfica, desenvolvida em nosso estudo, permite dar um tipo de visibilidade às dinâmicas interacionais textuais no chat, que podem ser lidas e interpretadas desde múltiplos olhares, ao abordar a comunicação verbal, via internet, em processos de ensinoaprendizagem.

Observamos que, enquanto as falas relativas ao pensamento bakhtiniano e ao relacionamento entre professor-aluno, mais atinentes aos objetos de estudo da disciplina cursada pelos alunos, concentraram-se da metade do chat até pouco antes de seu final, principalmente ao longo de seu pico interativo, os agenciamentos em torno do trabalho de conclusão da disciplina ocorreram praticamente durante todo o chat, com mais intensidade em sua primeira metade (apenas depois que uma certa quantidade de participantes já se encontrava na sala e até antes do pico interativo, quando, a um acordo tácito, dão espaço à maior interação relativa a objeto(s) da disciplina) e ao final do pico interativo

O ruído de enunciações curtas sobre amenidades ou de cordialidade, geralmente associadas aos movimentos (quase invisíveis) de entrada e saída de participantes, ocorre permanentemente ao longo do chat, saturando o pico interativo e predominando ligeiramente no final, ao apagar das luzes do chat.

A nítida convergência para discussões relevantes em relação aos eixos temáticos da disciplina ocorrida durante o chat, resultante tanto da ação indutiva de seu moderador como de direções espontaneamente assumidas por seus participantes, que denota, de pronto, a aderência por sua comunidade discursiva a uma ética implícita a presidir o transcurso do mesmo consoante a seus objetivos - validando, desta forma e neste caso, o chat como recurso pedagógico telemático síncrono.

Ora, tais fatos corroboram a visão de Axt (2006) a respeito de que, em modalidades de interação acadêmica mediadas por computador, como a do corpus nesse artigo analisado, pouco importa, para a instauração de uma comunicação discursiva dialógica, a ausência de um corpo, um rosto ou um olhar concretos, posto que os enunciados integrais que ali dialogam em sua expressão escrita tornam implicitamente presentes seus enunciantes, numa condição de presencialidade não-física.

Já o procedimento aqui descrito de representação espacial de intensidades e freqüências enunciativas em ambientes interativos 
virtuais, conquanto idealizado com o propósito inicial de auscultar e compreender apenas uma instância discursiva específica se constitui, a nosso ver, como ferramenta com potencial para sondagem e explicitação de padrões verificáveis em nuvens de enunciados em contextos virtuais.

Ao desenvolvermos um modo de representação de enunciados que ocorrem num ambiente de interação verbal num espaço tridimensional em que duas dimensões representam, respectivamente, o instante de ocorrência e a intensidade (extensão) de cada fala, alocamos a terceira (dimensão) para o estabelecimento de faixas ou categorias segundo as quais o pesquisador ache por bem classificar os enunciados que ocorrem no ambiente que Ihe serve de objeto de estudo, a procura de padrões significativos entre os mesmos. Em virtude das relações que quisemos elucidar ao longo do presente estudo, arbitramos, para seus diagramas, faixas categóricas discriminando, respectivamente, falantes (diagramas 2, 3 e 4) e eixos temáticos (diagramas 5, 6 e 7). Reiteramos, outrossim, o caráter eminentemente aberto da ferramenta, ao permitir ao pesquisador a utilização do eixo das categorias para quaisquer outras variáveis associadas a suas hipóteses de sondagem.

Outro objetivo que perseguimos no design do instrumento foi o recurso a ferramentas gráficas computacionais genéricas pré-existentes e de fácil utilização por usuários leigos, i.e., sem conhecimentos especializados em computação gráfica ou linguagens de programação. Sob este aspecto, o recurso ao MS Graphics, alimentado por tabelas geradas em Excel e compatível com os mais populares editores de documentos, apresentações e páginas da web (Word, Power Point e Front Page), se afigura como solução satisfatória. Desta forma, ao recorrermos, nas representações espaciais acima, à ferramenta gráfica de público domínio inclusa nos programas do MS Office, aspiramos não mais do que a concepção de um modo de ver enunciados aparentemente caóticas de um espaço interativo virtual que fosse capaz de mostrar possíveis relações entre os mesmos, quando agrupados segundo diferentes conjuntos de categorias.

Note-se, ainda, que diferentes opções de representação gráfica, dentre as muitas oferecidas pelo MS Graphics, apresentam distintos graus de adequação a cada tarefa. Desta forma, assim como optamos por barras verticais para representar enunciados individualizados segundo cada falante (diagramas 2, 3 e 4) ou superfícies onduladas para representar a continuidade de conversações temáticas paralelas (diagramas 5, 6 e 7); é possível a qualquer pesquisador, ao apropriar-se do instrumento, selecionar no versátil e auto-explicativo menu visual do software, o tipo de representação visual mais adequado aos padrões que queira realçar.

$\mathrm{Na}$ continuidade da pesquisa pretendemos analisar, com aporte da teoria da linguagem de Milkhail Bakhtin, os sentidos que atravessam as discussões conceituais no contexto das temáticas observadas no presente artigo, tendo em vista destacar as relações entre enunciações, a partir das quais as interações dialógicas configuram-se de determinados modos quando visualizadas nos gráficos.

\section{Referências}

AXT, Margarete. Comunidades Virtuais de Aprendizagem e Interação Dialógica: do corpo, do rosto e do olhar. Filosofia Unisinos, São Leopoldo, v. 7, n. 3, p. 256-268, set./dez. 2006.

AXT, Margarete; ELIAS, Carime Rossi. Autoria Coletiva, Ambientes Virtuais e Formação: de quando a aprendizagem reverbera o acontecimento. In: MARASCHIN, Cleci; FREITAS, Lia Beatriz; CARVALHO, Diana Carvalho de (Org.). Psicologia \& Educação: multiversos sentidos, olhares e experiências. Porto Alegre: Ed. da UFRGS, 2003. V. 1, p. 259-277.

AXT, Margarete et al. Interação Dialógica: uma proposta teórico-metodológica em ambientes virtuais de aprendizagem. RENOTE: revista novas tecnologias na educação, Porto Alegre, v. 4, n.1, jul. 2006.1 CDROM. 
BAKHTIN, Mikhail. Estética da Criação Verbal. São Paulo: Martins Fontes, 2003.

BARDIN, Laurence. Análise de conteúdo. São Paulo: Martins Fontes, 1988.

BERNARDES, Alexandra Sexto; VIEIRA, Paula Michelle Teixeira. No Discurso Produzido em Salas de Bate-Papo da Internet, a Descoberta de um Espaço de Produção de Linguagem. In: REUNIÃO ANUAL DA ASSOCIAÇÃO NACIONAL DOS PESQUISADORES EM EDUCAÇÃO, 24., 2001, Caxambu. Anais. Caxambu: ANPED, 2001.

CHIZZOTTI, Antonio. Pesquisas em Ciências Humanas e Sociais. 3. ed. São Paulo: Cortez, 1998.

MORAES, Roque; GALIAZZI, Maria do Carmo. Análise Textual Discursiva. Ijuí: Unijuí, 2007.

TODOROV, Tzvetan. Prefácio à Edição Francesa. In: BAKHTIN, Mikhail. Estética da Criação Verbal. São Paulo: Martins Fontes, 2003. P. xiii-xxxii.

Recebido em julho de 2008

Aprovado para publicação em setembro de 2008

\section{Augusto Maurer}

Professor do Departamento de Música do Instituto de Artes da Universidade Federal do Rio Grande do Sul (UFRGS), clarinetista da Orquestra Sinfônica de Porto Alegre, mestre em música pela Manhattan School of Music.

augustomaurer@gmail.com

\section{Paloma Dias Silveira}

Pedagoga. Mestranda em Educação do Programa de Pós Graduação em Educação da Universidade Federal do Rio Grande do Sul (UFRGS)

paloma.dias@gmail.com

\section{Tania Bischoff}

Psicóloga. Mestre em Psicologia Social e da Personalidade pela Pontifícia Universidade Católica do Rio Grande do Sul.

taniabischoff@gmail.com 